\title{
Hybrid power source based on heat and wind power plants
}

\author{
Valery Stennikov ${ }^{1}$, Andrey Penkovsky, ${ }^{1, *}$, and Ivan Postnikov ${ }^{1}$ \\ ${ }^{1}$ Melentiev Energy Systems Institute of the Siberian Branch of the Russian Academy of Sciences, \\ 664033, Lermontova str., 130, Irkutsk, Russia
}

\begin{abstract}
The technology of use of electric power of the wind power plants for direct replacement of fuel in the thermal cycles of the heat power plants is offered in the paper. The technology avoids solving the problems of ensuring the quality of electricity and the operational redundancy of the wind power in the power systems, as well as permits combining the achievements of traditional (gas turbine and steam and gas technologies, combined-cycle technologies and heating) and non-traditional renewable energy. The energy and environmental effects from the application of the proposed technology are shown, the technological advantages of the proposed schemes are considered, providing them with a wide scope of practical use both in local and in large power systems. The implementation and development of the proposed technology will allow extending and expanding business for manufacturers of steam turbine and gas turbine equipment, including the transition to the hydrogen power. The proposed technologies are protected by the patent.
\end{abstract}

\section{Introduction}

The wind energy, due to its wide prevalence and relatively high energy flux density, is the most promising resource of all non-traditional and renewable energy sources (RES) for many countries, including Russia. This is especially true for remote areas with expensive imported fuel. The wind energy trend covers already more than 70 countries. Only in the last 10 years the capacity of the wind power plants (WPP) in the world has increased by 10 times. The wind energy received the greatest development in the USA, Germany, China, India, Spain, Denmark, etc. So, by the beginning of 2016, the total installed capacity of all wind generators was $432 \mathrm{GW}$ [1]. By 2035, China plans to introduce $645 \mathrm{GW}$ of such power plants, the US and the European Union - $500 \mathrm{GW}$. The wind energy technology is a dynamically developing direction of alternative energy with a gradual expansion of the scope of application.

Unstable energy flow, which leads to a decrease in the quality of generated electricity and the stability the of EPS operation is the main technological problem of connecting the wind farm to the electric power systems (EPS). In connection with that, there is a growing need to reserve the power of the wind farm [2]. In the developed countries, the above issue is overcome through the use of actively developed Smart Grid technology [3].

\footnotetext{
${ }^{*}$ Corresponding author: penkoffsky@ isem.irk.ru
} 
Currently, the basis of the wind power (98\% of the total capacity of the wind power park) is the wind farms, operating in parallel with the EPS. This is mainly due to the fact that to some extent it became possible to solve the technical problems of including wind farms for parallel operation with the power system. To exclude significant distortions in the highest harmonic components in the voltage curve, filter-compensating devices are used when using asynchronous generators or frequency converters at the wind farms. In the current of the synchronous generator, the highest harmonic components are practically absent. However, in the case of using the wind farms with synchronous generators, one should take into account the possibility of voltage oscillations in the adjacent network. These oscillations can be smoothened by the application of automatic excitation controllers at the wind farms.

The operation of the wind farm as a part of EPS is usually done without the use of expensive accumulating and reserving devices due to their low share in the total power system capacity. However, because of the high rates of development of the wind power and the increase in its share in the total capacity of power systems, the problem of accumulation of electricity becomes one of the most important [4].

The solution of these issues, judging by foreign sources of information [5, 6, 7], based on years of experience in the design and operation of the wind farms, involves significant difficulties and additional costs. The ways of overcoming them are, as a rule, individual for specific wind farms and depend on the ratio of the wind farm and power system, the connection of the wind farm with the power system, the type of installation, the category of electricity consumers in this power supply area, the wind speed changes typical for the locality, etc. The experience of Denmark, the country that has achieved the greatest success in the use of the wind energy ( $20 \%$ of the electricity consumed by the country, is generated at the wind farms), indicates that the problem of regulating the current and voltage of the wind farms is the main one [4, 8]. And this is despite the fact, that Denmark has strong electrical connections with Europe and is characterized by large power of the hydropower plants. The analysis of the situation with the wind farms shows that at present the wind farms are mostly widespread in the areas of the centralized power supply covered by large EPS, although it is most advisable to use them (as well as other RES) in local EPS with expensive electricity and fuel. In many respects this is due to the difficulties of using the wind farms in small EPSs.

Without taking into account the hot reserve in EPS, the total capacity of the wind farm in the power system can make up only $1-2 \%$ of the total installed capacity without noticeable violation of the operating mode, that is comparable to the natural constant power balance fluctuations in the power system [8, 9] (although their overlap with amplification of the amplitude of oscillations is possible). Thus, for large energy systems (for example, of the type of EPS in Europe, that is, more than $500 \mathrm{GW}$ ), this amount can be thousands of megawatts, which is quite enough at the present stage of the wind energy development. However, the massive introduction of the wind farms worsens the dynamic stability of the power system: stochastic fluctuations in the generated power due to the changes in wind speed are imposed on changes in the demand for electricity. These factors require a significant change in the power regulation of the wind farms, especially large marine groups.

With the use of the wind farms in EPS, there is also a problem associated with the automatic re-inclusion of lines connecting the wind farms with the power system $[10,11]$. As practice shows, there is no proven technology that solves such problems in Russia. For example, the experiment conducted on the basis of the domestic wind farms ABE-250 and WTO-1250B showed that it is not expedient to use them on the criteria of the stability of work and the quality of electricity in the network that necessitates the development of a new type of the wind farms [12]. The situation is complicated by the fact that the regions of Russia that are promising for the development of wind energy are related, as a rule, to the areas of decentralized electricity supply. These areas have the greatest wind energy potential. 
The comparative analysis shows that power systems, which have a significant potential for using the wind farms in Russia, are small and often based on one or more small diesel power plants. In such EPSs, the quality of electricity, as a rule, is also low even without wind farms, and they do not have the ability to damp additional power fluctuations in the power system, which places high demands for generating sources, including the stability of the power output and the quality of electricity. Connecting even small wind farms to them requires the presence of parallel introduction of highly maneuverable duplicating capacities - diesel power plants or gas turbine plants, since there are practically no hydroelectric power stations in these areas, and, as a rule, there are no energy accumulators.

The technology of the wind energy use is mainly oriented at EPS, and until now it has not been considered for the heat supply systems (HSS). At the same time, this technology is no less relevant for HSS, which are the largest consumers of fuel, especially in Russia. Heat supply is the most fuel-intensive branch of the fuel and energy complex in Russia: more than $45 \%$ of the total consumption of fossil fuels is spent on its purpose, and the production of heat energy is 2 times higher than the production of electricity. The electrical and heat supply systems are deeply integrated. In addition, the most efficient for the climatic conditions of Russia heating (cogeneration) technology is used in the heat supply sector that provides significant savings of the organic fuels, obtained in the process of the combined production of thermal and electric energy at the cogeneration plants (CHPs).

\section{Technological schemes of joint operation of CHP and WPP}

The main idea of the proposed technological scheme is to unite in a single energy complex the wind farm with CHP running on the organic fuel, taking into account the peculiarities of power generation at the wind farm. Unlike the traditional scheme, it is proposed not to include the wind farms directly into the EPS network, but to use their electric power for direct replacement of fuel in the cycles of the thermal power plants of CHP. This approach was proposed by the team of authors within the framework of the patent for the invention [13]. In addition, the experience of development of the solar-fuel gas turbine plant $[14,15]$ can also be used in the proposed combined technology.

The schematic diagram of the integrated power supply complex implementing this technology on the basis of the steam turbine CHP (STU-CHP) and WPP is shown on the Figure 1. a) a Distinctive feature of this scheme is that additional steam overheating after the superheater of the steam boiler 1 is carried out by means of a thermal electric heater (PETN) 2 , powered by an electric generator of WPP 7. After that, the superheated steam, by further expansion, performs mechanical work in turbine 3 , driving the generator and generating electricity. Heat energy is supplied to consumers through the mains heater 21.

At the calculated wind speed, the developed WPP power is sufficient to ensure that PETN 2 provides that the steam is overheated to the required temperature. At the same time, PETN 2 is located in the base part of the power consumption of the wind farm, and the excess (in excess of the power of the heater) electric power of the wind farm is directed to the power supply of PETN 10, which warms the network water in front of the boiler house 11, reducing fuel consumption in its boiler. With insufficient (weak) wind strength, when the power developed by WPP becomes less than the power needed to overheat the steam in PETN, it switches to the backup power from the additional power source 9 with the help of the switch 8. This ensures a steady (stable) operation of both PETN 2 and STP in general, and their maximum efficiency, reliability and durability are achieved. Here, the experience of developing a solar-fuel GTP can be applied [5]. 


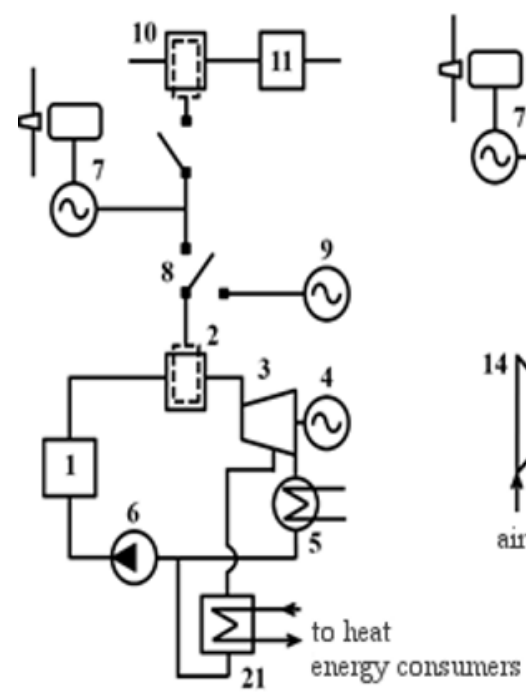

a)

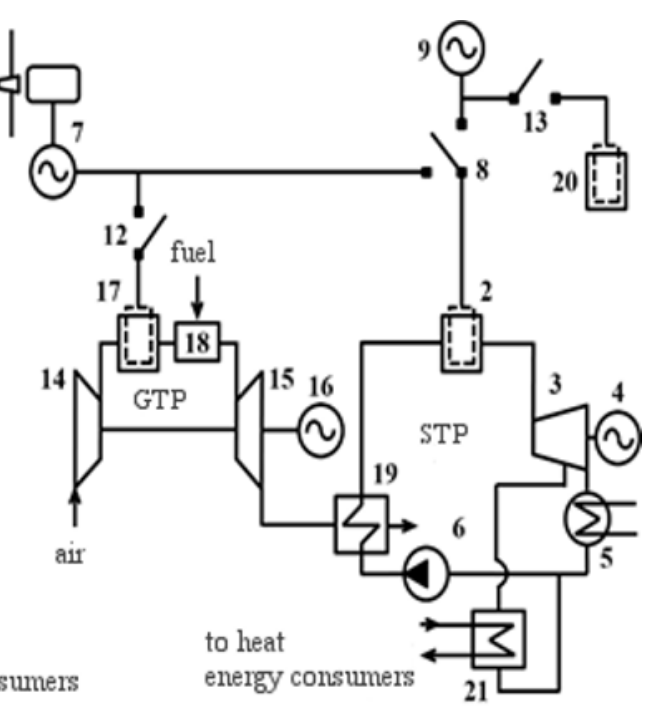

b)

Fig. 1. Schematic diagrams of the power supply systems based on CCGT-CHP and WPP (a) and CCGTCHP and WPP (b): 1 - steam boiler; 2 - PETN of CCGT; 3 - steam turbine; 4 - generator of CCGT; 5 turbine condenser; 6 - feeding pump; 7 - wind farm (WPP); 8-switch of the heater of the STP; 9 - reserve source of electricity; 10 - PETN of the network water; 11 - boiler house; 12-switch of PETN of GTP; 13-ballast switch; 14 - compressor of GTP; 15 - gas turbine; 16 - generator of GTP; 17 - PETN of GTP; 18 - combustion chamber of GTP; 19-boiler-utilizer; 20 - ballast loading; 21 - network heater.

As a reserve source of electricity, electric power accumulators (EPA) in the form of batteries and condenser batteries, flywheel, pumped storage, pneumatic EPA, fuel cells on accumulated hydrogen and other possible electric power accumulators, and power plants on organic fuel - internal combustion engines, diesel, gas turbine, CCGT unit, fuel cells on natural gas, liquid fuel, etc. can be used. To smooth the sharp fluctuations in the energy source power, small capacity batteries of capacitive or inductive type can be set at the entrance of PETN.

In order to achieve maximum reliability of the power supply of PETN 2 (hence, the work of the whole STP-CHPP), it is planned to pre-emptively switch it to the power from a backup source 9, which is calculated on the basis of statistical data of operating modes of a particular wind farm and meteorological forecasts. For example, such switching can be carried out in the case when the power of the wind farm becomes only 5-10\% higher than the required power of PETN 2. This is necessary in order to exclude the situation of insufficient power of the wind farm for the power supply to the heaters of the STP because of the instability of the wind, its sharp (within a fraction of a second) fluctuations within 5-10\% of the required value. Provision is also made for the reverse process of switching the PETN 2 to the power from the wind farm upon reaching its power level by $10 \%$ of the power of PETN 2.

The Figure $b$ shows the scheme of the power supply complex that implements the integrated technology in the combined-cycle power plant (CCGT-CHPP) and the wind farm. The technological scheme provides for the preliminary start-up and the preparation for the operation of the backup source of electricity 9, for which, before switching to the power supply of PETN of the STP 2, it is switched on to the ballast load 20. And only when the backup power source acquires the nominal power and enters the stationary mode, it is switched from the ballast load on PETN of the STP 2. During the output to the nominal mode, the backup power source 9 is switched to the ballast load 20 by the switch 13. Upon reaching the stationary mode, the source 9 switches off from the load 20 by the switch 13 , and at the 
same time by the switch 8 it switches to the power supply of PETN 2. This allows excluding the influence of the inertia of the backup source on the provision of PETN 2 with the required amount of electricity. The ballast load can be made in the form of PETN that heats the water in the heat network.

\section{The enlarged analysis of the effectiveness and advantages of the proposed technologies}

The enlarged technical and economic assessment of the use of the wind farms with a capacity of $500 \mathrm{~kW}$ for direct fuel replacement in the CCGT-CHP cycle in the coastal regions of the North-West of Russia is shown in the Table 1. It advises that, with the existing economic indicators, the use of the wind farms is economically viable. At the same time, in severe climatic conditions, specific requirements are imposed on the mechanisms; therefore, there may be some rise in price of the wind farms due to "the northern option" with the use of special materials to ensure its reliable operation at low temperatures. It is even possible to develop a special design of WPP to reduce dynamic loads on the plant elements and the influence of cold brittleness of materials on the reliability of the plant.

Table 1. Formatting sections and subsections.

\begin{tabular}{|c|c|}
\hline Indicator, unit. & Value \\
\hline Capacity of WPP, $\mathrm{kW}$ & 500 \\
\hline Warranty period, years & 25 \\
\hline Cost of equipment, \$ thousand & 495 \\
\hline Cost of construction and installation works, \$ thousand & 140 \\
\hline Additional costs (PETN, power lines, etc.), \% & 10 \\
\hline Installed capacity utilization ratio, \% & 45 \\
\hline Savings of diesel fuel, t/year & 467.5 \\
\hline Cost of diesel fuel, \$ thousand/t & 0.4 \\
\hline Reduction of CO emissions, t/year $_{2}$. & $1496^{*}$ \\
\hline Cost of fuel saved, \$ thousand/year & 187 \\
\hline Depreciation costs, \$ thousand/year & 71.7 \\
\hline Operating costs, \$ thousand/year & 2.0 \\
\hline Growth of balance sheet profit, \$ thousand/year & 113.5 \\
\hline Increase in net income, \$ thousand/year & 73,8 \\
\hline Simple rate of return, \% & 103 \\
\hline Simple payback period, years & 4,8 \\
\hline
\end{tabular}

*calculated on the basis of "Specific $\mathrm{CO}_{2}$ emission $\mathrm{kg}_{\mathrm{CO} 2} / \mathrm{kg}_{\text {fuell }}$ " for diesel fuel [16].

The main effect of this integrated technology is a fuel economy, and therefore $\mathrm{CO}_{2}$ emission reduction. However, the proposed integrated schemes of CHP+WPP have many other advantages, among which the following can be distinguished:

1. EPS is guaranteed to receive high-quality electricity from the generators of STU-CHP or CCGT-CHP regardless of changes in the wind power. At the same time, there is no reduction in the quality of electricity in the network, also because of the transients when the wind farm is turned on/off.

2. There is no need for parallel additional maneuverable power covering the base loads. This often leads to a corresponding waste of fuel, which can block the fuel savings from the use of WPP. The units used in the CCGT+WPP complex can participate in covering both the base and maneuvering load, working with high fuel efficiency.

3. Instead of a number of wind power plants included in the EPS and reducing its stability, 
a relatively large CHP plant appears that increases this stability.

4. The use of WPP for heat supply allows compensating the increased heat loss in strong winds, providing, in the most windy periods, peak energy production for heating, because the wind, as it is known, is the second after the outside air temperature climatic parameter that determines the volume of heat consumption.

5. There is a possibility of implementation of the energy production of many wind farms on one or several CCGT-CHP by a local electric network with a gradual increase of the capacity of the wind farms and consumers of the unstabilized electricity.

6. The inclusion of WPP in the electrical network via a STU-CHP and CCGT-CHP allows avoiding the problems of ensuring power quality and operational reserve of the WPP capacity in EPS.

7. Wind power can be used in the combined heat and power generation plants of high quality and a wide range of power, including small CHP. Herewith, many technological restrictions on the use of WPP are removed [17]. In particular, the capacity of WPP can exceed the total capacity of power plants and boilers in power supply systems. The development of wind power is becoming independent of the technical requirements of the EPS, the owners of WPP and the operators of power networks have no direct points of contact, and the commercial efficiency of WPP will depend to a minimum on the system restrictions, tariffs and modes of operation of EPS.

8. The implementation of the proposed technological schemes allows explicitly assessing the real energy and economic effect of the use of WPP. When WPP is directly connected to a centralized power network that is most often implemented in practice, the impact of WPP on the efficiency of EPS is difficult to assess, since in this case the efficiency is assessed at the level of the power system as a whole.

9. The electric networks connecting the CHP+WPP complexes with EPS and the electricity consumers are used more efficiently with the line load factor of up to $100 \%$ instead of $30-35 \%$ in the case of direct supply from WPP, since the CHP+WPP complex produces a stable flow of electricity of the required quantity and quality.

\section{Conclusions}

The proposed integrated scheme of power supply on the basis of CHP and WPP allow combining achievements of traditional (steam turbine and steam gas) and renewable energy, and not to oppose them to each other, as it is usually done in practice, when WPP has to compete with fuel-efficient CCGT-CHP. The use of the integrated systems such as CCGT+WPP removes the issue of competition of these technologies, and the synergetic effect of their integration only increases. Substitution, for example, 50\% of the fuel used in CCGT-CHP with the unstabilized electricity of WPP is more favorable in the respect energetics than two-fold increase in the efficiency of the gas turbine part of the CCGT-CHP, because the same fuel consumption of thermal and electrical capacity of CCGT+WPP will be higher.

High-quality fuel at its current cost for the European consumers at the level of 9-15 \$ / GJ can be replaced by WPP electricity at the cost of 3-5 cents/kWh. Electricity of modern WPP costs 3-6 cents / $\mathrm{kWh}$, therefore, taking into account the above factors, the potential cost of WPP reduction, it seems that the economic efficiency of the wind energy use under the scheme of CCGT+WPP is already achievable at the present time, and it will increase with the expansion of the efficiency zone as the cost of fuel goes up, as well as with improving the WPP technology and increasing the scale of their use.

In view of the significant potential of future development of the wind power, WPP will force highly economical basic CHP to move to maneuvering mode of work with a corresponding reduction of their fuel efficiency, since any accumulation of electricity will 
lead to an increase in costs, and in the annual context it is almost impossible. In this regard, the proposed technology of CHP+WPP represents a real alternative to the existing power supply schemes [18], and its implementation will significantly expand the scope of the wind farm application, increase competitiveness and contribute to reducing investment and operating costs for their construction and exploitation.

The proposed technology can be integrated into any structure of generating capacity and can be implemented on the basis of the Russian equipment. The most promising direction is the use of the proposed schemes in the autonomous power supply systems. The attractiveness of the power generation complexes of the CHP+WPP type increases in connection with the apparent trend of expanding use of distributed energy sources on the basis of small CHP and local RES, as well as the inevitability of transition of the global energetics to RES with the transmission of large amounts of electricity of WPPs from the Arctic to the industrialized areas $[19,20]$.

In Russia, the integrated power supply schemes based on CHP and WPP are focused primarily on the use in the autonomous power systems of the Far East and the Far North, formed on the basis of local networks of unstabilized electricity and combining WPP, CCGTCHP and boilers. In these systems, they have a real opportunity to maximally displace the organic fuel with the wind energy. In this regard, the proposed technology is intended primarily for the creation of power complexes on the basis of small CHP (with a capacity of not more than $25 \mathrm{MW}$ ). With introduction of the CHP+WPP technology, the reliability and security of the energy supply to remote areas will increase due to the guaranteed minimum of energy supply to the population, even with possible fuel shortages.

At the same time, for large CHPs the proposed technology is no less promising with a reasonable optimal ratio of the capacities of CHP and WPP, taking into account the modes of electric and thermal energy supply. As the practice of operation of such power complexes develops, they will have good prospects for use in large power systems, especially in view of the increasing cost of fuel and improvement of technical and economic indicators of the WPP application.

Implementation and development of the proposed technology will contribute to the development of the CCGT producers, including the transition to hydrogen energy. The proposed technology will ensure sustainable development of energetics and economics on the basis of an optimal balance of expensive and scarce traditional fuels, and RES technologies that are getting cheaper, combined with increasing environmental friendliness and availability of energy [21].

The research has been done within the framework of the research project III.17.4.1 of the SB RAS Program of Basic Research, reg. No. AAAA-A17-117030310432-9.

\section{References}

1. Global Wind Energy Council, Global wind statistics 2015 (http://www.gwec.net/wpcontent/uploads/vip/GWEC-PRstats-2015_LR.pdf, 2015)

2. J. Vanzetta, Energy Abroad - Aupplement to the "Energetik" magazine,1, 2-14 (2016)

3. H. K. Meden, Energy: Economics, Technology, Ecology, 4, 2-8 (2004)

4. RZ Energetika, Concept of renewable energy in the new lands of Germany (1991)

5. RZ Energetika, Joining the wind farm to the power grid (Denmark) (1991)

6. RZ Energetika, Parallel work of wind power plants with power system (1984)

7. J. G. Slootweg and W.L. Kling, IEEE Power\&Energy, 6, 26-33, (2003)

8. VA Light, Energy and Electrification, 4, 16-18, (1985) 
9. RZ Energetika, Operation in conditions of expansion of the fleet of wind power plants (2003)

10. Yu. G. Shakaryan, A. V. Pikovsky, Power Engineering, 3, 46-48 (1991)

11. I. I. Ilinykh, A. B. Lose, Power Engineering, 3, 55-62 (1991)

12. D. E. Kadomsky, Power Engineering, 20, 8-9, (1992)

13. S. V. Zharkov, A. V. Keiko, I. V. Postnikov, A. V. Penkovsky. Method of operation of the steam turbine plant. Patent number 2557049, registered on July 20, 2015 (Irkutsk, 2015).

14. P. Heller, M. Pfander, T. Denk, F. Tellez, A. Valverde, J. Fernandez, A. Ring, Solarenergy, 80 (10), 1225-1230 (2016)

15. R. Buck, P. Schwarzbözl, Gas Turbo Technology, 2, 17-21 (2009)

16. D. Yaşar. Energy: Production, Conversion, Storage, Conservation, and Coupling (University of Nebraska Lincoln, Lincoln, NE, USA, 2015)

17. L. Hirth, The Energy Journal, 36(1), 149-184 (2015)

18. Z. Yuan, L. Hao, Y. Wang, Energy Policy, 37, 1736-1744 (2009)

19. C. Liu, Global Energy Association (MPEI Publishing House, Moscow, 2016)

20. A. V. Bogoviz, S. V. Lobova, Y. V. Ragulina, A. N. Alekseev, International Journal of Energy Economics and Policy, 8(3) 67-75 (2018)

21. A. E. Kontorovich, Science First-Handed, 2, 6-25 (2014) 